University of Nebraska - Lincoln

DigitalCommons@University of Nebraska - Lincoln

2018

Autologous Bone Flap Resorption Years After Subtemporal

Craniotomy

John Oladapo Obafunwa

Emily E. Hammerl

David Jaskierny

Livia A. Taylor

Lynette Russell

See next page for additional authors

Follow this and additional works at: https://digitalcommons.unl.edu/natresreinhard

Part of the Archaeological Anthropology Commons, Ecology and Evolutionary Biology Commons, Environmental Public Health Commons, Other Public Health Commons, and the Parasitology Commons

This Article is brought to you for free and open access by the Natural Resources, School of at DigitalCommons@University of Nebraska - Lincoln. It has been accepted for inclusion in Karl Reinhard Papers/ Publications by an authorized administrator of DigitalCommons@University of Nebraska - Lincoln. 


\section{Authors}

John Oladapo Obafunwa, Emily E. Hammerl, David Jaskierny, Livia A. Taylor, Lynette Russell, and Karl Reinhard 


\title{
Autologous Bone Flap Resorption Years After Subtemporal Craniotomy
}

\author{
John Oladapo Obafunwa, MBBS, FMCPath, FWACP, \\ DMJPath, FRCPath, FFPathRCP(I), LLB, FCLM, FFFLM,* \\ Emily Hammerl, $\mathrm{PhD},+$ \\ David Jaskierny, MD, $\neq$ \\ Livia Taylor, MS, ${ }^{\dagger}$ \\ Lynette Russell, MS,§ \\ Karl Reinhard, PhD*
* Forensic Science Program, School of Natural Sciences, University of Nebraska-Lincoln
+ Department of Anthropology, University of Nebraska-Lincoln
₹ Pathologist and Coroners Physician, Omaha, Nebraska
$\S$ Criminal Investigation Unit, Lincoln Police Department, Lincoln, Nebraska

Correspondence email: joobafunwa@hotmail.com

\begin{abstract}
:
In Spring of 2012, the partially undressed and skeletonized remains of a homeless adult Hispanic male was found in a fairly open wooded area in Nebraska. The remains showed evidence of extensive pathologies, which included healed traumas and surgeries. Examination of the decedent's medical records revealed that he had a history of kidney and liver problems, alcohol abuse, several traumas including a major head injury that necessitated a craniotomy, and radiological features of neurocysticercosis. The autologous bone flap, which was replaced after the craniotomy, had resorbed significantly away from the edges of the injury. Death was variously
\end{abstract}

Published in Am J Forensic Med Pathol, Volume 39, Number 2, June 2018, pp 179-183.

DOI: 10.1097/PAF.0000000000000389

Copyright (C) 2018 Wolters Kluwer Health, Inc. Used by permission.

Submitted August 18, 2017; accepted January 6, 2018. 
attributed to craniocerebral injury with hypothermia sequel to blunt force trauma most probably due to a fall. The manner of death was ruled as an accident. This study makes use of the forensic evidence and medical records to examine the possibility that the unique combination of failed cranioplasty, hypothermia, and neurocysticercosis may have contributed to the victim's death. Other potential causes of death are considered.

Keywords: cause and manner of death, blunt force trauma, fall, neurocysticercosis, craniotomy, cranioplasty, bone flap resorption, hypothermia

Forensic anthropologists are faced with a variety of unique challenges, many of which stem from an inherent dearth of available data. In any event where a forensic anthropologist is required, it can be assumed that significant data have already been lost, largely in the form of soft tissue. The task of conclusively reconstructing cause and/or manner of death from skeletal remains may in many cases prove impossible. It is common practice for the police and the coroner or chief medical examiner's office to seek the assistance of the forensic anthropologist in determining the cause and manner of death during the examination of buried bodies or secondary to the discovery of skeletonized or burnt remains. Some of the usual contributions include providing answers as to the age of the remains (ancient or modern), human or nonhuman, sex, stature, age at death, race, osteopathologies, and determination of characteristic features and injuries. ${ }^{1}$

Victim identification is generally aided by antemortem records of osteopathology, prosthesis, and portable identifiers such as clothing, jewelry, and documents contained in recovered wallets; positive identification involves the use of forensic odontology and DNA studies. Although identification eventually did not pose a challenge in the present case, the police and forensic team had to use the skeletal evidence combined with information gleaned from the decedent's medical records to develop a hypothesis as to what led to this individual's demise.

\section{Case history and findings}

In the Spring of 2012 in the Lancaster County of Nebraska, the partially undressed and partly skeletonized remains of an adult male was found in a fairly open wooded area by a man walking his dog, and 


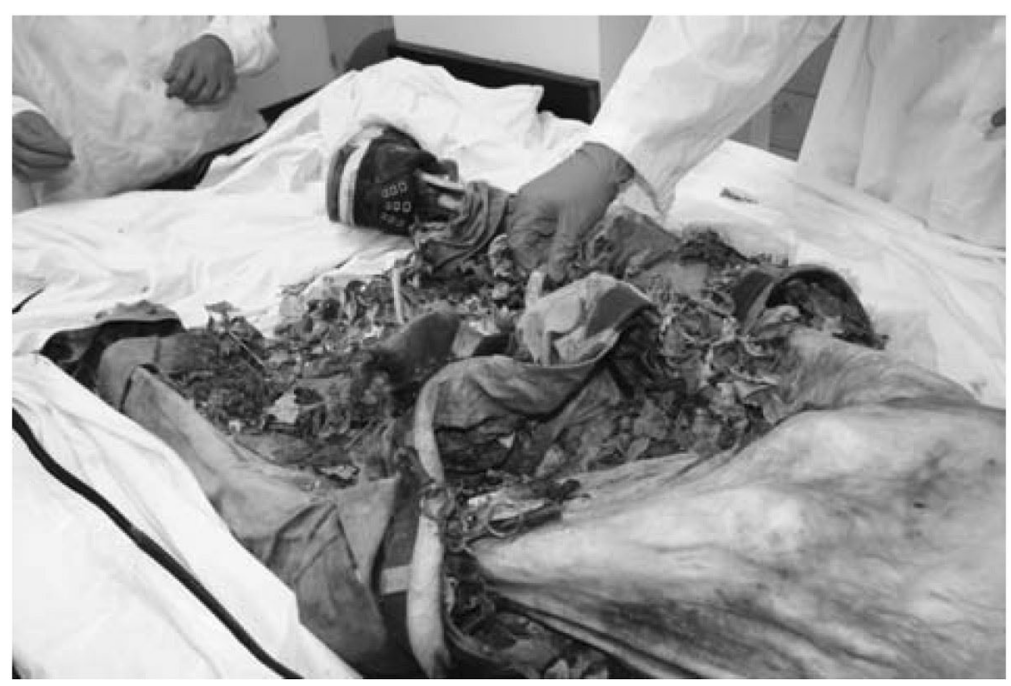

Figure 1. Remains as received in the laboratory. Note the khaki pants situated around the mid-thigh position.

he reported his find to the Police Department. The Criminal Investigation Unit initially handed the remains to the pathologist, who after his examination handed the remains over to the forensic anthropology team at the University of Nebraska- Lincoln for further analysis. The local forensic odontologist was also invited to partake in the investigation. Examination of the scene revealed a wallet in the decedent's pocket, and an empty bottle of alcohol was found around the body. The wallet contained a name suspected to be that of the victim. The victim was unclothed around the torso down to the pelvic area (Fig. 1). The decedent was skeletonized from the lower lumbar spine to the cranium; the body below the fourth lumbar vertebra was mummified. The legs were still partially clothed in a pair of khaki pants; the police had retrieved from the scene skeletonized elements including the carpal bones.

The pelvic girdle, legs, and feet were defleshed in the Forensic Science Pollen Laboratory, and the bones were treated with a hot solution of water and papain. Adherent soft tissues were further removed with spatulas, forceps, and scalpels.

\section{Anthropological and Odontological Findings}

Forensic anthropological and odontological evaluations were done independently and without the knowledge of the police analysis of 
physical evidence such as the wallet and subsequent identification. Anthropological analysis revealed the remains to be that of a male decedent aged 45 to 65 years at the time of death, with a height of approximately $5 \mathrm{ft} 6 \mathrm{in}$., and likely to be of Latino origin. The determination of ethnicity was based on nonmetric cranial traits, and several characteristics suggested Hispanic origin. ${ }^{2}$ These included shoveled incisors, which were noticeable even after cosmetic abrasion of the anterior teeth. The malar exhibits a moderate anterior projection. The frontal process of the zygomatic bone is wide. The nasal sill is somewhat blunted. Finally, the molars exhibited a planar wear consistent with a diet of stone ground food and coarse plant elements such as phytoliths. ${ }^{3}$ This sort of diet is consistent with rural areas of Mexico. Dental wear was consistent with a diet rich in stone-ground flour and/ or food rich in plant-derived abrasives. In the authors' experiences, this was most consistent with diets rich in stone-ground flour and prickly pear. Other findings are described hereinafter.

\section{Skeletal Evidence of Antemortem Trauma and Pathology}

Long-Healed Blunt Force Trauma and Craniotomy With Life-Threatening Consequences

The cranium exhibited an old craniotomy site over the right temple. The area contains healed radiating and crescentric fractures extending outward from the posterior and superior margins of the craniotomy. This indicates that the craniotomy was sequel to a severe blunt force blow to the right side of the head. The severity of the blow was such that the zygomatic arch (cheek bone) was fractured and had to be surgically wired to the frontal and temporal bones. The process of craniotomy involves surgical removal of a section of the bone from the skull. This is called a bone flap that is replaced after the decompression surgery directed at reducing the intracranial pressure caused by the brain swelling or the accumulation of blood or fluid. The replacement of the bone depends on the clinical situation; it could be during the same surgery or at a later elected date. The restoration (cranioplasty) could also be done by using a synthetic material. The observation of a bone flap in the decedent suggested that he must have sustained a blunt force trauma with possible intracranial bleed. 


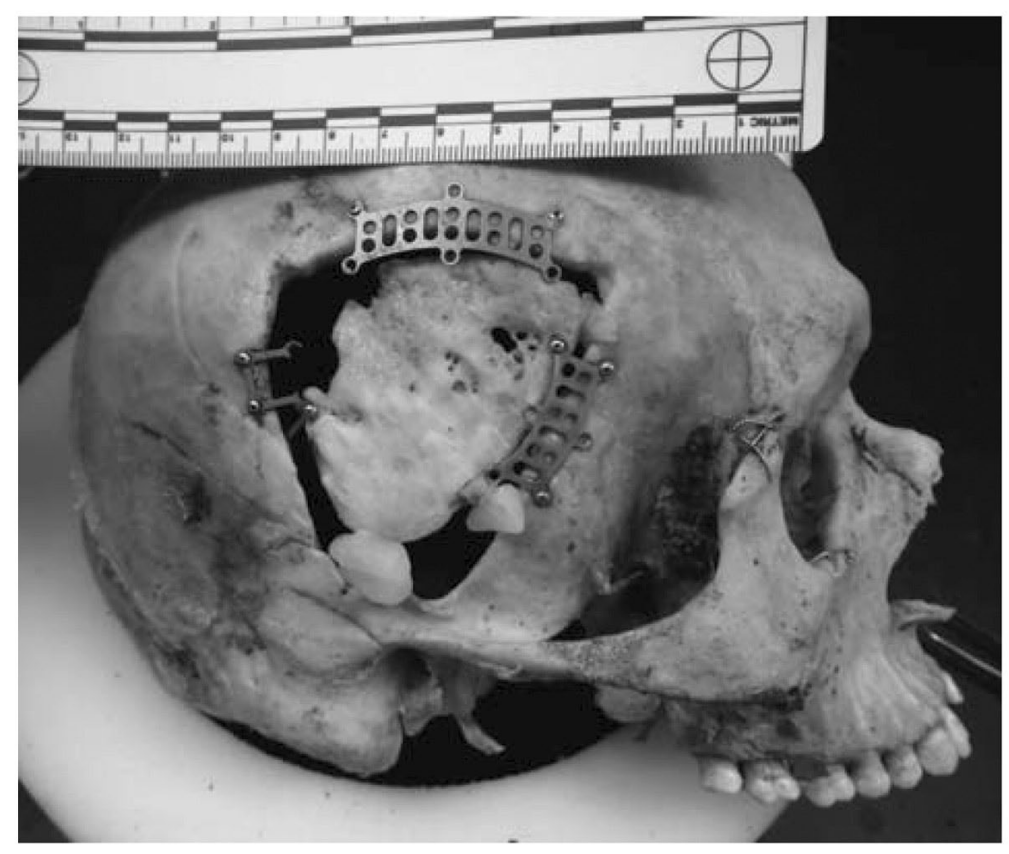

Figure 2. Right side of the skull showing the cranioplasty site with bone flap resorption. Note the missing screws and the wax supports to display the size of the area of resorption toward the occipital direction, after more than a decade of surgical repair. The lateral and inferior margins of the right orbital bone have also been surgically wired.

The craniotomy site was roughly triangular, measured $6.1 \mathrm{~cm}$ at the top and $1.9 \mathrm{~cm}$ at the base, and with a vertical height of $6.6 \mathrm{~cm}$. It was apparently originally held in place using 4 braces bridging the bone flap and the rest of the skull; in other words, there would have been 8 screws, considering that 2 would be required per brace. Three of these braces were still screwed to the skull, whereas 1 was missing. The bone flap revealed resorption; the edges had resorbed away from the margin of the rest of the skull and separated by a distance varying from 0.3 to $3.0 \mathrm{~cm}$, with only 3 screws being in contact with the flap. The latter was also thinned to just $1 \mathrm{~mm}$ in places along its edge (Figs. 2, 3). Thus, during his lifetime, there would have been a free-floating, blade-like triangular bone next to the decedent's brain. This would have been life threatening if even minor pressure or impact was applied to that part of the skull. The superior cranial vault was thinned both interiorly and exteriorly in the sagittal region just posterior to the coronal suture. Distinct pits were observed endocranially, independent of pacchionian depressions (Fig. 4). 


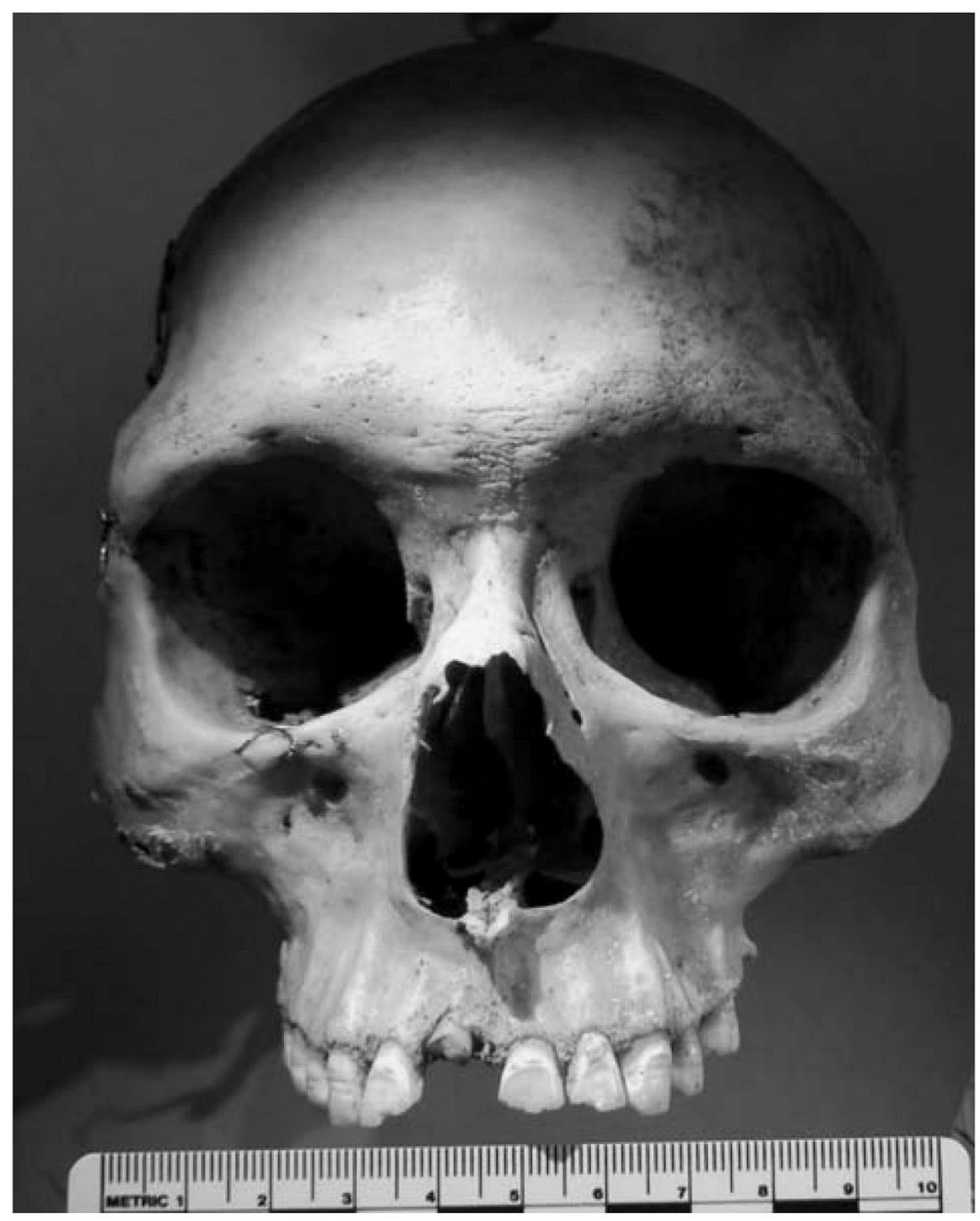

Figure 3. Anterior view of the skull showing the wire stitches on the lateral and inferior margins of the right orbit.

\section{Cosmetic Polishing of the Upper Teeth}

The decedent exhibited linear enamel hypoplastic lines on all his remaining unaltered teeth. These grooves on his teeth could have resulted from periods of childhood stress such as fever or malnutrition. He had the enamel polished off his upper incisors and canines, presumably for cosmetic reasons.

\section{Dental Pathology}

Based on alveolar remodeling and lack thereof, the decedent had lost the left upper second and third molars some weeks before death, 


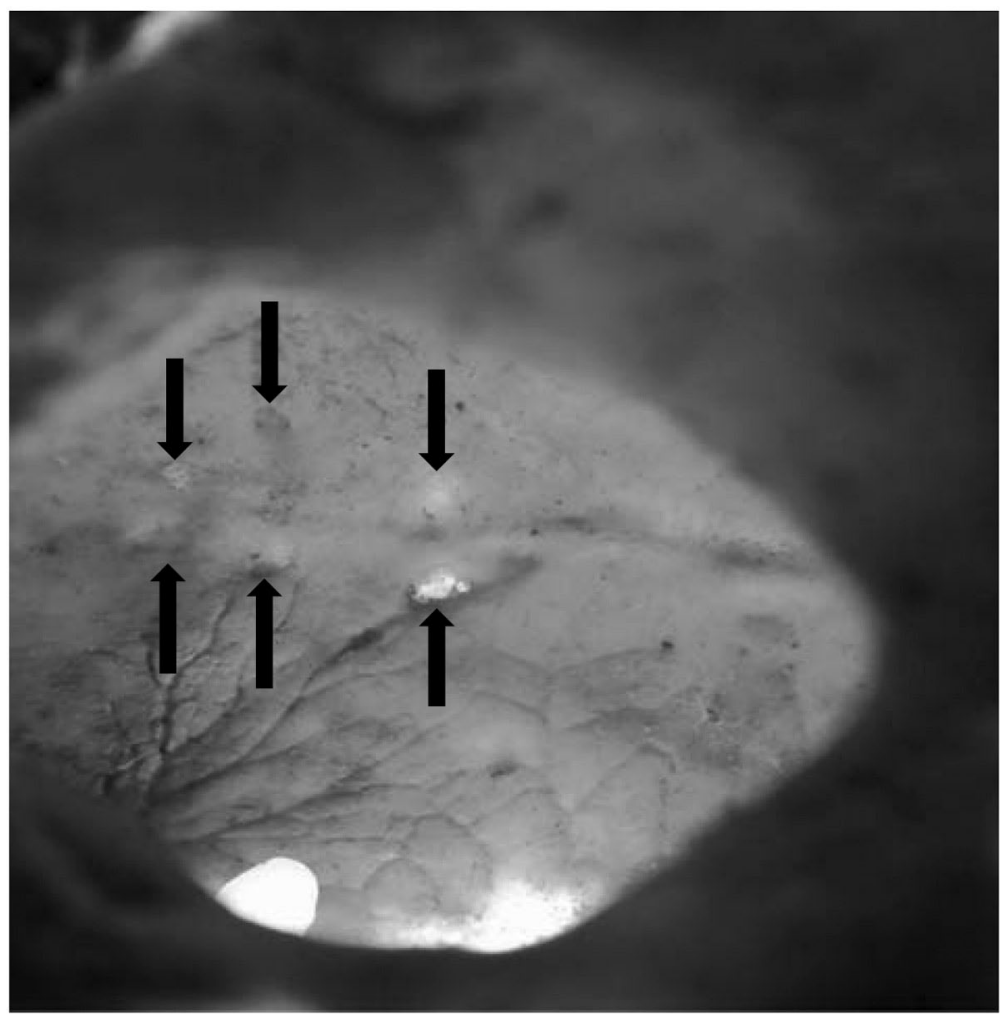

Figure 4. Internal view of the cranial cavity through the foramen magnum and showing the endocranial pits (arrows).

and the upper second premolar long before death. The right central incisor appears to have been broken and the root is still in the socket. In the mandible, the left first molar exhibits decay and one root remains in its socket. The left lateral and central incisor were lost postmortem. Most of the remaining teeth exhibit severe occlusal wear.

\section{Shoulder Reconstruction Surgery}

The heads of both humeri of the shoulder joints have been reconstructed by surgical resurfacing of the joints.

\section{Healing Fracture of the Left Foot}

There is a healing fracture of the left talus articulation with the calcaneus. This fracture must have occurred a few weeks before death. 


\section{Osteoarthritic and Other Degenerative Disease}

The mid and lower spine as well as most of the bone of the extremities exhibit arthritic joint surfaces, roughened muscle attachment, ossifying tendons, and osteophytosis apparently due to strenuous activity during his lifetime.

\section{Perimortem Trauma}

None was found.

\section{Postmortem Trauma}

The right distal humerus has been damaged by animal activity. Two ribs exhibit fractured sternal ends, probably due to animal activity.

\section{Medical Records}

The police had found a wallet in the decedent's pants which contained information suggesting the victim's identity with the date of birth. Based on the anthropological findings and toward determining the cause and manner of death, the police approached the local hospital for any medical records between 1991 and 2010. According to the decedent's medical records, he was born in northern Mexico and his family moved to Texas after which he moved to Nebraska, where he had been a known homeless person.

He was admitted into the hospital in June of 2000 after having fallen from a wall and suffered from a head injury while having a blood alcohol level of $266 \mathrm{mg} / \mathrm{dL}$. The fall resulted in a large, depressed, comminuted fracture to the right temporal and parietal bones; epidural and subdural hematomas with dural, cortical, and intraparenchymal lacerations; and brain swelling. A computed tomographic (CT) scan revealed skull fracture involving the right temporal bone with further fragmentation inferiorly; there was upward extension to the right parietal bone and inwardly into the right petrous bone. Also noted on neuroimaging were 3 small rounded hypodensities in the upper parts of both parietal lobes of the brain, and each of these contained tiny internal densities with little adjacent parenchymal edema. There were also few suspected tiny calcifications on both sides. Although these findings radiologically 
suggested neurocysticercosis, the acute intracranial injury was apparently the immediate focus of clinical management.

An emergency subtemporal craniotomy was performed to evacuate the hematomas, elevate the depressed fracture, and control residual bleeding. Bone fragments were also removed. Laceration of the brain was seen, there was brain swelling, and some oozing was noted from the areas of laceration. Surgicel and Gelfoam were applied over the torn brain tissue and bleeding sites. The bone flap was plated during the same surgical procedure and a drain was inserted the bleeding surgical site. The wound was closed up and an antibiotic dressing was applied. Radiological examination of the neck bones revealed mild degenerative changes.

A repeat $C T$ scan performed 5 days after the surgery revealed some resolution of the bleeds and again focal punctate calcifications within the cerebral hemispheres with a clinical suspicion of neurocysticercosis. However, there is no record of a serological confirmation. The intraparenchymal bleed had reduced, but some residual blood and edema were still present at these sites. He was discharged to the Rehab care Unit after a week following surgery, at which time he was having some headaches but no seizures. The patient was advised to abstain from alcohol and to avoid falls. He was finally discharged from the unit after another 8 days.

The medical records revealed no additional hospital attendance until October 2010, when he was admitted with cellulitis of the left leg which was suspected to have been caused by a spider bite. He was commenced on antibiotics. At admission, he was found to be obese, had fatty liver, and exhibited glucose intolerance with a hemoglobin A1C level of 6.5. There was mention of a resolved acute renal failure. He was discharged after 9 days with antibiotics, analgesics, and topical dermatological applications. There were no further entries in the clinical notes.

\section{Cause of Death}

Death was attributed to craniocerebral injury with hypothermia secondary to a proximate blunt force trauma. This conclusion was reached after evaluation of the pathological anthropological, odontological, and radiological findings, coupled with the medical records. Additional possibilities are discussed hereinafter. 


\section{Manner of Death}

The scene examination, combined with the partially disrobed remains, indicated that the decedent was in the process of undressing. This suggested paradoxical undressing which would be associated with hypothermia. There was no evidence from the scene or from the police investigation that indicated foul play or suspicious activity. This individual's campsite was isolated from more established homeless camps. Therefore, violent interaction was not suggested. The medical records yielded important background information. Based on all these, the manner of death was in the first instance considered to be an accident. Additional possibilities are also further discussed hereinafter.

\section{Discussion}

The identification of the victim was not an issue in the present case. The discovery of a wallet on the remains and the subsequent review of the clinical notes all corroborated the forensic anthropological and dental findings, thus simplifying the task of identification. The dental analysis was done by a certified forensic odontologist.

The cause of death became more complicated from the point of discovery to the final assessment. The unhealed cranioplasty drew attention from the very beginning of the investigation. However, the medical records not only assisted with the interpretation of the skeletal findings but also provided additional information on other factors possibly contributing to the cause and manner of death.

Most noteworthy, the medical notes revealed radiological features compatible with neurocysticercosis, but no further investigation including serological tests was considered. Apparently, because the primary focus was on the acute brain injury that occurred on June 2000, further corroboration of the radiological evidence of neurocysticercosis was passed over. Also, it is very easy to lose a homeless person with respect to hospital follow-up, and as such, it is not surprising that the decedent was not seen in the same hospital until 2010. Neurocysticercosis is a parasitic infection of the brain tissue of pork eaters by the larva form of Taenia solium; these include Cysticercus cellulosae and Caulerpa racemos. These larvae migrate to the central nervous system, eyes, and striated muscle believed to be sites with high 
levels of glycogen and glucose. ${ }^{4} \mathrm{~A}$ report of 11 patients showed that seizure was the most common presenting symptom in all of them. ${ }^{4}$ There were calcified brain lesions in 2 patients, CT scan showed parenchymal cysts of less than $<2.0 \mathrm{~cm}$, and magnetic resonance imaging showed hypointense cortical lesions. The prevalence of this infection varies according to geographical locations; it is common in Mexico, Central and South America, India, and Sub-SaharanAfrica. ${ }^{5}$ Constant emigration northward from Mexico would explain the rising incidence in the United States. ${ }^{6-9}$ The risk of contracting this infection is increased among the poor, the Hispanic population, and among males. The decedent in this case was a homeless man who emigrated from northern Mexico and showed characteristic radiological lesions, but unfortunately, the condition was not serologically confirmed. However, the presence of noncalcified cysts suggests that the infection may have been active; calcified cysts contain dead parasites. Given that neurocysticercosis is known to have a latent or inactive period of up to several years, it is possible that the symptoms had simply not yet begun to manifest ${ }^{9}$ at the time of surgery. The forensic team could not completely exclude the possibility that this condition had existed and had contributed to the failure of the bone flap to heal properly. It is possible that the bone flap got compressed by a fall after a neurocysticercosis-induced seizure or acute alcohol intoxication with supervening hypothermia. The authors also considered the possibility of a blow to the head in a "struggle" with consequent craniocerebral trauma. However, it is noteworthy that no perimortem fractures were readily identified.

The decedent in 2000 underwent a decompressive craniotomy, which was immediately followed by autologous bone repair during the primary surgical procedure. Unfortunately, the hospital notes in 2010 did not make any reference to the status of this repair done 10 years earlier. When the remains were found in 2012, very significant bone flap resorption was discovered. The bone flap had resorbed to such an extent that only 3 of the original 8 screws used to secure the flap to the surrounding area of the skull were even in contact with it. The bone flap was separated from the edges of the craniotomy by a distance ranging from 0.3 to $3.0 \mathrm{~cm}$. Three to 6 metal screws would have been freed from the bone as the flap resorbed. It is conceivable that one or more of these screws became displaced toward the brain. 
Autologous bone resorption is not an uncommon complication of cranioplasty as shown by several case reports and studies. ${ }^{10-19} \mathrm{~A}$ number of risk factors have been associated with this complication of cranioplasty. Age is an independent risk factor, and the younger the patient ( $<2.5$ years), the greater the risk of developing bone flap resorption. ${ }^{10,11,13,16,19} \mathrm{~A}$ retrospective study showed that cranial defects greater than $120 \mathrm{~cm}^{2}$ often result in bone resorption. ${ }^{16}$ In the case of children, defects smaller than $75 \mathrm{~cm}^{2}$ do not result in resorption. ${ }^{10}$ Aseptic necrosis and infections are recognized risk factors. ${ }^{11,18}$ This risk is also associated with injuries accompanied by acute subdural hematoma, postoperative effusion, underlying contusion of the brain tissue, and when there is a requirement for the insertion of a shunt as with hyrocephalus. ${ }^{13-17}$ Furthermore, resorption is often associated with cases where the fracture has resulted in multiple fragmentations of the skull bones. ${ }^{11-13,19}$ Naturally, it is expected that angiogenesis with bone growth (osteogenesis) will be disrupted by bone fragmentation coupled with widened interval between the apposed bone edges during surgery. These risk factors add to the number of complications the decedent could have faced and indeed could have contributed to his demise.

The decedent in this case underwent decompressive craniotomy, intracranial hematoma, cortical laceration, and cranial bone fragmentations, and there was intraoperative and postoperative bleeding with oozing of blood that required application of Surgicel and Gelfoam. All these were against a background of radiologically diagnosed neurocysticercosis. One known effect of neurocysticercosis is hydrocephalus due to blockage of cerebrospinal fluid by ependimitis, arachnoiditis, and formation of ventricular cysts sequel to the inflammatory reaction. ${ }^{20-22}$ The build-up of cerebrospinal fluid leads to increased intracranial pressure and will consequently interfere with bone healing through failure of union between the bone flap and the adjoining normal bone due to the persistent gap. These factors are fertile grounds for bone flap resorption. It is possible that the decedent's bone flap began resorbing soon after its implantation, and the resorption was not noticed because of a lack of follow-up care. However, it is noteworthy that the rate of resorption cannot be said to have been rapid in the present case because it was still incomplete after more than a decade after the surgery. Noticeable resorption of autologous bone flaps has been observed to occur within a year or less, and in one 
case, the bone flap had nearly completely resorbed within 5 months. ${ }^{14}$ When it is considered that he was a known homeless alcoholic, it is not difficult to appreciate why he could easily experience a fall. The likelihood of severe or fatal brain injury is thus increased should this occur over a bone flap exhibiting resorption. This background medical status coupled with the absence of any suspicious findings at the death scene would explain the conclusion of the forensic investigators that the manner of death was an accident.

Of great significance is the time of the year and findings at the scene. The remains were found toward the end of the 2011/ 2012 winter months; the time since death was estimated to be 3 to 4 months. The partially clothed nature of the victim would immediately suggest paradoxical undressing, a phenomenon that is associated with hypothermia. ${ }^{23-25}$ Hypothermia results when the core body (rectal) temperature falls to or below $35^{\circ} \mathrm{C}\left(95^{\circ} \mathrm{F}\right)$, which is approximately $2^{\circ} \mathrm{C}$ below the normal body temperature. However, the condition becomes severe with core temperatures lower than $28^{\circ} \mathrm{C}\left(82.4^{\circ} \mathrm{F}\right)$; it is not uncommon to have ambient temperatures falling below $0^{\circ} \mathrm{C}\left(32^{\circ} \mathrm{F}\right)$ during winter months in Nebraska. Some of the risk factors associated with fatal hypothermia include exposure to low environmental temperatures and/or damp conditions as might be encountered among the homeless, children, and the elderly; impairment of the central nervous system with uncontrolled loss of consciousness; chronic alcoholism; acute alcohol intoxication; conditions that might allow for hypoglycemia such as starvation; and diabetes mellitus. ${ }^{24-26}$ The decedent was a known homeless and alcoholic (an empty bottle of alcohol was found around the body), and he had a preexisting cranioplasty with bone flap resorption against a background of neurocysticercosis. He could easily have had an accidental fall while intoxicated, had further head injury, lapsed into unconsciousness, and ultimately died of hypothermia, in the course of which he had exhibited paradoxical undressing. This latter phenomenon is usually associated with temperatures between $-5^{\circ} \mathrm{C}$ and $+5^{\circ} \mathrm{C}\left(23^{\circ} \mathrm{F}-41^{\circ} \mathrm{F}\right)$ where victims tend to have a paradoxical feeling of warmth. ${ }^{27,28}$ Although this scenario might fit very well into the conclusion that death was accidental, the authors are aware that a natural event such as a neurocysticercosis-induced seizure or a homicidal situation precipitated by a fall if struck on the head by an assailant cannot be completely excluded. Considering these possibilities and decomposition of the remains, the exact cause of death can be ruled as undetermined. 


\section{Conclusions}

This was a rather challenging case in the context of deciding the cause (including other possibilities or contributing factors) and the possible manners of death. The forensic team's conclusion was going to determine whether or not the police would have to commit lots of resources into a suspected case of homicide. Although identification was not a challenge, the medical records released a Pandora's box of natural events. However, the death scene investigation, anthropological findings, and the explanations deduced from the medical records as it relates to neurocysticercosis, complications of cranioplasty, and the likelihood of an accidental fall during the winter months caused the investigators to eventually conclude that death was accidental. Of course the possibility of a natural event or homicide cannot be ignored. The retrospective conclusion in this case further reinforces the need for the forensic pathologist to continue to draw on medical, dental, and anthropological data in considering the possible causes and manners of death. The practitioners should try to explain and justify their conclusion while avoiding bias and maintaining an open mind.

The authors report no conflict of interest.

No organization funded this report.

\section{References}

1. Nawrocki SP. An outline of forensic anthropology. University of Indianapolis Archeology \& Forensic Laboratory. 1996. Available at: http://archlab.unindy. edu. Accessed June 27, 2006.

2. Birkby WH, Fenton TW, Anderson BE. Identifying Southwest Hispanics using nonmetric traits and cultural profile. J Forensic Sci. 2008;53:29-33.

3. Hammerl EE, Baier MA, Reinhard KJ. Agave chewing and dental wear: evidence from quids. PLoS One. 2015;10:e0133710.

4. Kuruvilla A, Pandian JD, Nair M, et al. Neurocysticercosis: a clinical and radiological appraisal from Kerala State, South India. Singapore Med J. 2001;42:297-303.

5. Flisser A. Neurocysticercosis in Mexico. Parasitol Today. 1988;4:131-137.

6. Mc Cormick GF. Cysticercosis: review of 230 patients. Bull Clin Neurosci. 1985;50:76-101.

7. Scharf D. Neurocysticercosis. Arch Neurol. 1988;45:777-780. 
8. Camera ML, Durack DT. Helminthic infections. In: Scheld WM, Whitley RJ, Durack DT, eds. Infections of the Central Nervous System. 2nd ed. Philadelphia: Lippincott-Raven Publishers; 1997:845-878.

9. White AC. Neurocysticercosis: a major cause of neurological disease worldwide. Clin Infect Dis. 1997;24:101-105.

10. Grant GA, Jolley M, Ellenbogen RG, et al. Failure of autologous bone-assisted cranioplasty following decompressive craniectomy in children and adolescents. J Neurosurg. 2004;100:163-168.

11. Dunisch P, Walter J, Sakr Y, et al. Risk factors of aseptic bone resorption: a study after autologous bone flap reinsertion due to decompressive craniotomy. J Neurosurg. 2013;118:1141-1147.

12. Schuss $P$, Vatter $H$, Oszvald $A$, et al. Bone flap resorption: risk factors for the development of a long-term complication following cranioplasty after decompressive cranioplasty. J Neurotrauma. 2013;30:91-95.

13. Bowers CA, Riva-Cambrin J, Hertzler DA 2nd, et al. Risk factors and rates of bone resorption in pediatric patients after decompressive craniectomy for traumatic brain injury. J Neurosurg Pediatr. 2013;11:526-532.

14. Yin J, Jiang Y. Completely resorption of autologous skull flap after orthotopic transplantation: a case report. Int J Clin Exp Med. 2014;7: 1169-1171.

15. Honeybul S, Ho KM. Decompressive craniectomy for severe traumatic brain injury: the relationship between surgical complications and the prediction of an unfavourable outcome. Injury. 2014:1332-1339.

16. Lee $\mathrm{SH}$, Yoo CJ, Lee $\mathrm{U}$, et al. Resorption of autogenous bone graft in cranioplasty: resorption and reintegration failure. Korean J Neurotrauma. 2014; 10:10-14.

17. Kim JS, Cheong JH, Ryu Jl, et al. Bone flap resorption following cranioplasty after decompressive craniectomy: preliminary report. Korean J Neurotrauma. 2015;11:1-5.

18. Stieglitz LH, Fung $C$, Murek $M$, et al. What happens to the bone flap? Long-term outcome after reimplantation of cryoconserved bone flaps in a consecutive series of 92 patients. Acta Neurochir. 2015;157:275-280.

19. Brommeland T, Rydning PN, Pripp AH, et al. Cranioplasty complications and risk factors associated with bone flap resorption. Scand J Trauma Resusc Emerg Med. 2015;23:75.

20. Matushita H, Pinto FC, Cardeal DD, et al. Hydrocephalus in neurocysticercosis. Childs Nerv Syst. 2011;27:1709-1721.

21. Del Brutto OH. Neurocysticercosis. Neurohospitalist. 2014;4:205-212.

22. Bouteille B. Epidemiology of cysticercosis and neurocysticercosis. Med Sante Trop. 2014;24:367-374.

23. Lim C, Duflou J. Hypothermia fatalities in temperate climate: Sydney, Australia. Pathology. 2008;40:46-51.

24. Turk EE. Hypothermia. Forensic Sci Med Pathol. 2010;6:106-115.

25. Palmiere C, Teresinski G, Hejna P. Postmortem diagnosis of hypothermia. Int J Legal Med. 2014;128:607-614. 
26. Teresiński G, Buszewicz G, Madro R. Biochemical back-ground of ethanolinduced cold susceptibility. Leg Med (Tokyo). 2005;7:15-23.

27. Wedin B, Vanggaard L, Hirvonen J. Paradoxical undressing in fatal hypothermia. J Forensic Sci. 1979;24:543-553.

28. Sivaloganathan S. Paradoxical undressing and hypothermia. Med Sci Law. 1986;2:225-229. 